\title{
Thermal Behavior of an Improved Face-Grinding Spindle: Water-Lubricated Hydrostatic Thrust Bearing Decreases Temperature Rise and Increases Axial Stiffness
}

Shuyun Jiang ( $\square$ jiangshy@seu.edu.cn )

Southeast University

Shengye Lin

Southeast University

Fukang Liu

Southeast University

\section{Research Article}

Keywords: face-grinding spindle, water-lubricated hydrostatic thrust bearing, rolling bearing, thermal modeling, finite element method

Posted Date: January 20th, 2022

DOI: https://doi.org/10.21203/rs.3.rs-1259196/v1

License: (c) (1) This work is licensed under a Creative Commons Attribution 4.0 International License.

Read Full License 


\title{
Thermal Behavior of an Improved Face-Grinding Spindle:
}

\section{Water-Lubricated Hydrostatic Thrust Bearing Decreases Temperature Rise and}

\author{
Increases Axial Stiffness \\ Shuyun Jiang ${ }^{1}$ Shengye Lin Fukang Liu \\ School of Mechanical Engineering, Southeast University, Nanjing, 211189, P R China
}

\begin{abstract}
Axial thermal deformation and axial stiffness are main technical indicators to affect manufacturing accuracy of face-grinding spindle. However, the face-grinding spindle supported by rolling bearings lubricated with grease has a relative disadvantage in respect of temperature rise, axial stiffness and rotational accuracy. To overcome this issue, this study proposes a novel face-grinding spindle supported by a combined bearings, which include a water-lubricated hydrostatic thrust bearing and two rolling bearings with oil-air lubrication system. The thermal model for the proposed face-grinding spindle is established and the spindle thermal behavior is analyzed systematically. An experiment prototype of the face-grinding spindle is developed, and temperature rise of the spindle is detected to verify the thermal model. The result shows that the temperature rise of the proposed spindle can be decreased by the using of the water-lubricated hydrostatic thrust bearing. A comparative study between the two types of spindles shows that the proposed face-grinding spindle with the combined support has technical advantage of low temperature rise, large axial stiffness and low rotation accuracy, etc.
\end{abstract}

Key words: face-grinding spindle; water-lubricated hydrostatic thrust bearing; rolling bearing; thermal modeling; finite element method.

\section{Introduction}

Manufacturing accuracy of face-grinding spindle is closely relative to axial thermal deformation and axial stiffness. Rolling bearings are currently utilized to support the face-grinding spindles [1]. At present, the workpiece size increases continuously, so the rolling bearings with large size have been utilized to support the spindle [2]. It should be noted that, with the increasing of the rolling bearing size, the friction heat generation of the bearing increases, and the rotation accuracy of the bearing becomes large. To solve this issue, this paper proposes an improved high-speed face-grinding spindle supported by a combined bearings, which consists of a water-lubricated hydrostatic thrust bearing and two rolling bearings lubricated by oil-air lubrication system. The main design objective is to reduce the temperature rise and improve the axial stiffness. The proposed face-grinding spindle has multiple heat sources and heat dissipation, so it is essential to establish a thermal model for the proposed spindle so as to carry out a thermal analysis.

Until now, there has been an increasing amount of literature on thermal analysis of machine tool spindle system. The research objects mainly include spindles supported by rolling bearings [3-19], spindles supported by hydrostatic bearings [20-25], and spindles supported by hydrodynamic bearings [26,27]. Modeling methods adopted mainly include: finite

\footnotetext{
${ }^{1}$ Corresponding author Email: jiangshy@seu.edu.cn; Tel. 86-25-52090533
} 
difference method [5,6], thermal resistance network method [3,4,7,16], bond graph method[18, 19], and finite element method [8-15, 17, 20, 23-27]. In their studies, temperature distribution and thermal deformation were calculated using the above methods [3-20, 22-27]. Experimental research includes two aspects: one is measuring temperature rise of spindles by temperature sensors or thermal imagers [3, 4, 7-18, 20, 21, 23, 25-28]; another is measuring thermal deformation using displacement sensors [8-18, 20, 22, 24-26, 28].

Together, progress in thermal analysis of spindle system has been made by scholars. However, as for the proposed face-grinding spindle with hydrostatic thrust bearing and rolling bearings, the main challenges are faced for the thermal modeling: (1) Centrifugal effect of lubricating water in hydrostatic thrust bearing is prominent at high rotation speed, the influence of which on flow field cannot be neglected; (2) Shear velocity of lubricating water in the large-diameter thrust bearing varies significantly along radius direction, thus the influence of which on temperature rise of lubricating water should be considered; (3) Convection heat transfer between rolling bearings and oil-air lubrication is a complex process; the flow state of oil-air lubrication is turbulent.

In this study, the thermal model for the proposed face-grinding spindle is established. Firstly, equilibrium equation of flow rate for the water-lubricated hydrostatic thrust bearing is set up considering pressure flow, centrifugal flow and shear flow; heat generation of rolling bearings is deduced based on formula of friction torque; and thermal boundary condition of the spindle components is calculated using heat transfer theory. Secondly, thermal model for the spindle system is established using finite element method, and the thermal characteristics is predicted by aid of a commercial software. Thirdly, an experimental prototype for the proposed face-grinding spindle is developed, and temperature rise of the spindle is measured to verify the thermal model. Finally, a comparative study of comprehensive characteristics between the spindle supported by rolling bearings and the replacement spindle designed with proposed combined support is conduct to illustrate the advantage of the proposed one.

\section{Physical description and design objective}

Figure 1 shows a schematic view of the face-grinding spindle supported by the water-lubricated hydrostatic thrust bearing and the rolling bearings. The water-lubricated hydrostatic thrust bearing locates at the right end of the spindle, the shaft is radially supported by a self-aligning ball bearing and a deep groove ball bearing with a pair of O-ring rubbers, and the rolling bearings are lubricated by a oil-air lubrication system.

The design objective for the proposed face-grinding spindle is as follows:

1) Reduce the temperature rise of the spindle

Considering that the water-lubricated hydrostatic thrust bearing has low temperature rise due to its low viscosity and large flow rate, this study aims to reduce the temperature rise of the spindle by employing a water-lubricated hydrostatic thrust bearing. Furthermore, in view of rotor dynamics, rotational stiffness of thrust bearing is capable of increasing radial stiffness of spindle, so the rolling bearings in small-size can be operable for the proposed spindle when a large-size water-lubricated hydrostatic thrust bearing is introduced. The smaller the rolling bearing size, the lower the friction power loss. Especially, the oil-air lubrication system can reduce the heat generation due to its minimal quantity lubrication and bring out the majority of heat from the rolling bearings.

2) Improve the axial load-carrying capacity

The axial load-carrying capacity of the spindle can be improved by increasing thrust disc diameter and water supply pressure. 
3) Decrease the axial motion error

Since the hydrostatic bearing has lower motion error compared to the rolling bearings due to the film homogenization effect, the proposed spindle with the water-lubricated hydrostatic thrust bearing can obtain a lower axial motion error than that with rolling bearings.

In summary, the design objective of the proposed spindle includes a comprehensive performance such as a low temperature rise, a large axial load-carrying capacity and a low axial motion error, etc.

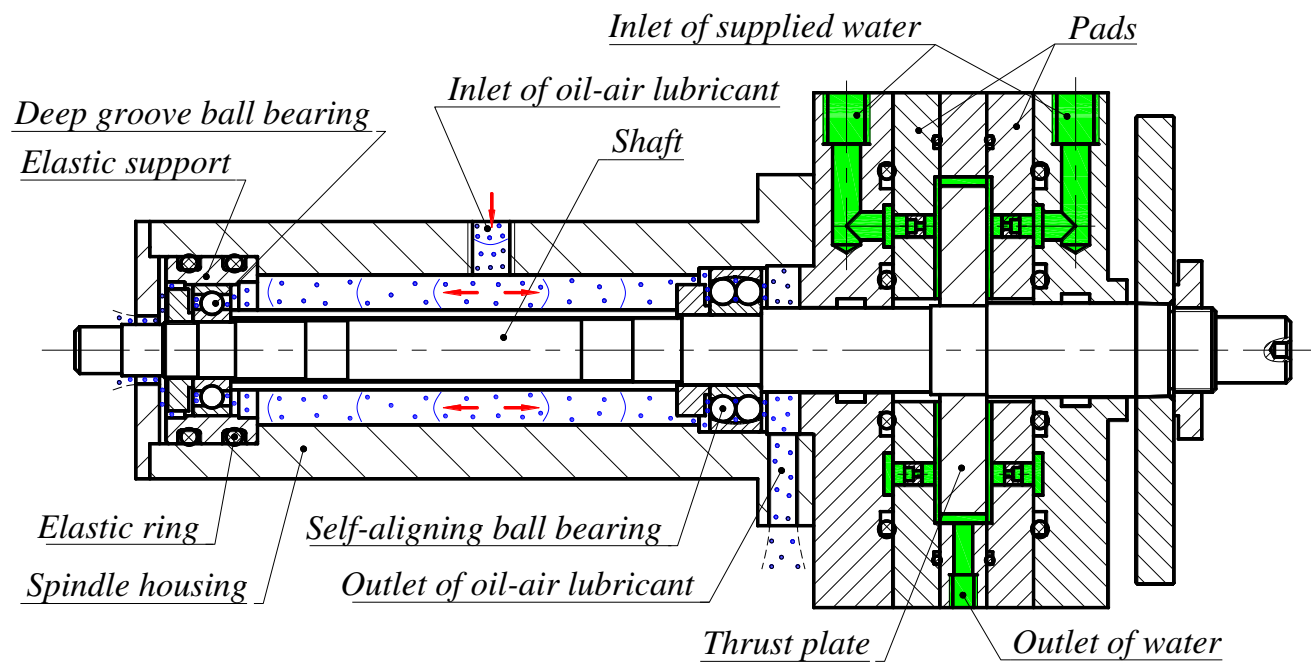

Fig. 1 Schematic of the proposed face-grinding spindle

\section{Thermal modelling}

\subsection{Power flow model}

A power flow model for the proposed spindle system is shown in Fig.2. In this model, the power enters the spindle system $\mathrm{P}_{\text {mech in }}$ is partly used to overcome the bearing friction $\left(\mathrm{q}_{\mathrm{brg}}\right)$; the rest of the power $\left(\mathrm{P}_{\text {mech out }}\right)$ is used for cutting and acceleration. The bearing friction power loss $\left(\mathrm{q}_{\mathrm{brg}}\right)$ is transformed into heat, which is transferred into the shaft ( $\left.\mathrm{q}_{\text {shaft }}\right)$, the lubricant $\left(\mathrm{q}_{\mathrm{lub}}\right)$, the thrust bearing $\left(\mathrm{q}_{\text {thrust }}\right)$, and the rolling bearings $\left(\mathrm{q}_{\text {rolling brg }}\right.$ ). For the purpose of this study, heat generated by water-lubricated static thrust bearing $\left(\mathrm{q}_{\text {thrust }}\right)$ and rolling bearings ( $\mathrm{q}_{\text {rolling brg }}$ ) are the main heat sources of the spindle system.

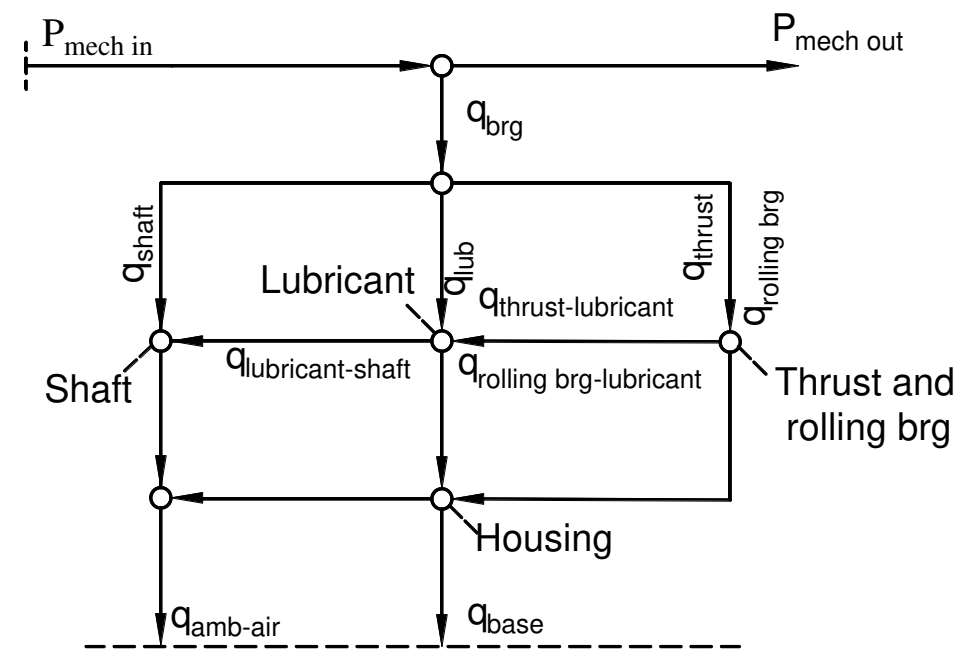

Fig. 2 Power flow model for the proposed spindle 


\subsection{Heat source}

\subsubsection{Heat generation of the water-lubricated hydrostatic thrust bearing}

The heat generation of water-lubricated hydrostatic thrust bearing mainly results from water film shearing and hydraulic power delivered by water pump, which is related to the water film thickness, spindle rotation speed, water flow rate, and feeding pressure of water pump. In this section, the heat generation by pressure flow is neglected due to its accounting for a small percentage of total heat generation. Compared with the oil, the water viscosity changed hardly with the temperature rise, and the test result in this study shows that temperature rise of the water-lubricated hydrostatic thrust bearing is less than $2^{\circ} \mathrm{C}$, so the water viscosity can be approximatively constant. Therefore, in this study, the typical energy equation for the fluid bearing is not included when modelling.

1) Friction heat power

To model the heat generation resulting from water film shearing in the water-lubricated hydrostatic thrust bearing, the following assumptions are introduced:

(1) Water is Newtonian fluid, following Newton's internal friction law;

(2) The friction heat of hydrostatic thrust bearing is carried away by water;

(3) Compared with heat generation in seal dam, heat generation in water recess can be neglected;

(4) The water film of the thrust bearing along the axial direction is isothermal;

(5) Variation of water viscosity with temperature can be neglected;

(6) Considering that the water viscosity changes hardly with temperature rise and temperature rise in this study is in a small amplitude, the water viscosity is assumed as a constant.

Figure 3 shows a schematic of water-lubricated hydrostatic thrust bearing. The polar coordinate system is adopted in the platform of thrust pad, as shown in Fig.3(b), the positive direction is the counterclockwise direction.
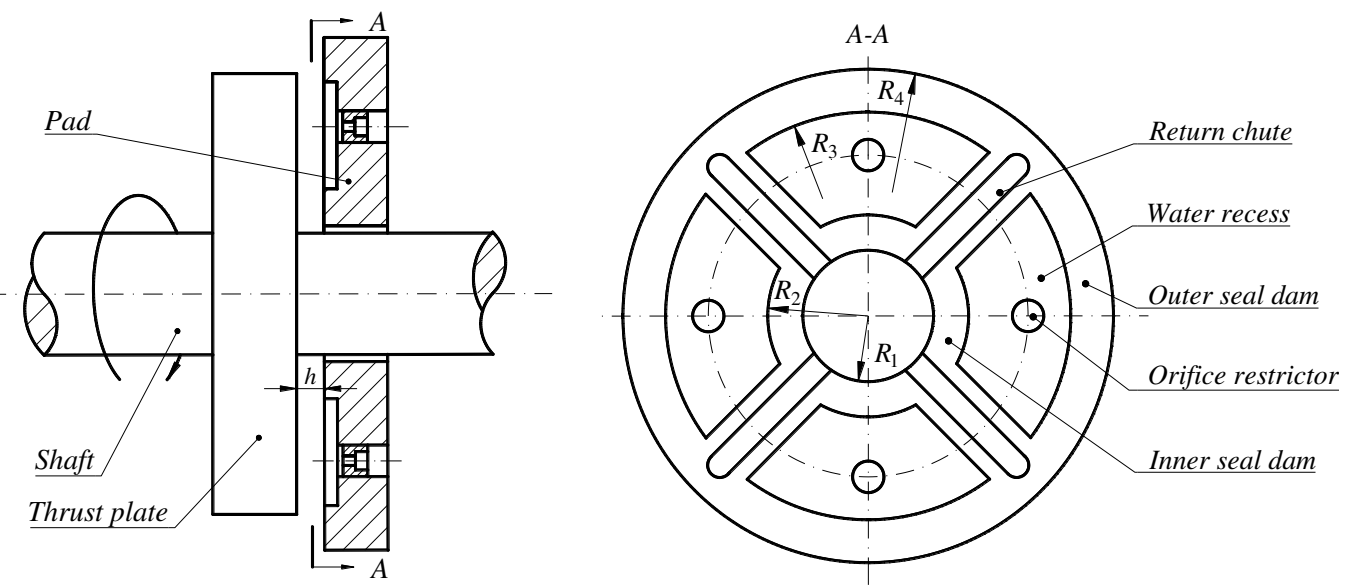

(a) Thrust bearing 


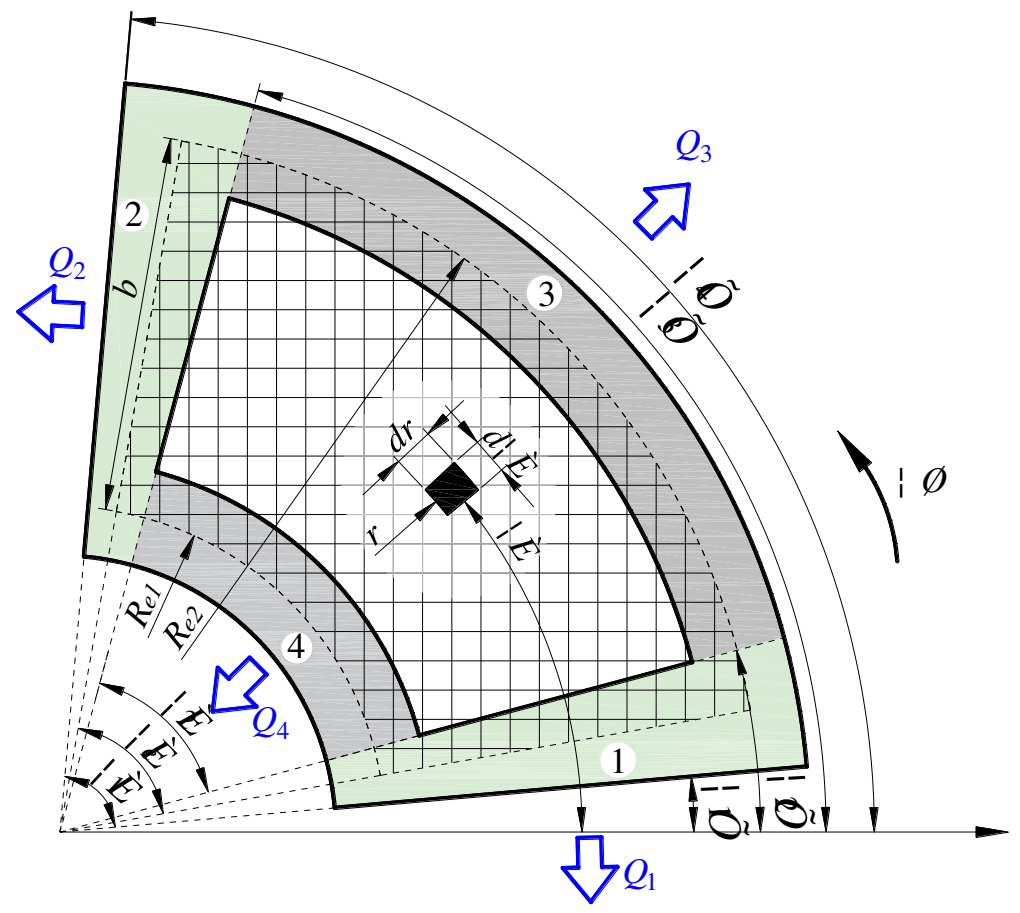

(b) One platform of thrust pad

Fig. 3 Schematic of water-lubricated hydrostatic thrust bearing

Circumferential velocity of the differential element $\mathrm{d} \theta-\mathrm{d} r$ is

$$
v=\omega r=\frac{\pi n r}{30}
$$

Shear stress of the differential element $\mathrm{d} \theta-\mathrm{d} r$ is

$$
\tau=\mu \frac{v}{h}
$$

Friction force of the differential element $\mathrm{d} \theta-\mathrm{d} r$ due to water film shearing is

$$
d F=\mu \frac{v}{h} r d r d \theta
$$

Friction heat power of the differential element $\mathrm{d} \theta-\mathrm{d} r$ is

$$
d N_{f}=v \mu \frac{v}{h} r d r d \theta
$$

Friction heat power of a certain area is obtained by surface integral as follows

$$
N_{f}=\iint \mu \frac{\omega^{2} r^{3}}{h} d r d \theta=\frac{\mu \omega^{2} r^{4}}{4 h}
$$

The four integral domains according to the seal dam regions are marked 1, 2, 3, and 4, as shown in Fig.3(b), and then the corresponding friction heat powers are given as follows

$$
\begin{aligned}
& N_{f 1}=\mu \frac{\omega^{2}\left(R_{4}^{4}-R_{1}^{4}\right)}{h}\left(\varphi_{2}-\varphi_{1}\right) \\
& N_{f 2}=\mu \frac{\omega^{2}\left(R_{4}^{4}-R_{1}^{4}\right)}{h}\left(\varphi_{4}-\varphi_{3}\right)
\end{aligned}
$$




$$
\begin{aligned}
& N_{f 3}=\mu \frac{\omega^{2}\left(R_{4}^{4}-R_{3}^{4}\right)}{h}\left(\varphi_{3}-\varphi_{2}\right) \\
& N_{f 4}=\mu \frac{\omega^{2}\left(R_{2}^{4}-R_{1}^{4}\right)}{h}\left(\varphi_{3}-\varphi_{2}\right)
\end{aligned}
$$

2) Flow rate and hydraulic power of water pump

As shown in Fig.3(b), the shaded area represents the effective load-carrying area of the bearing. Lubricating water enters recess through restrictor and then flows out through seal dam region. In this case, flow state of lubricating water is laminar considering that the Reynolds number is less than 2300

The angle of the effective load-carrying area is

$$
\theta_{e}=\left(\theta_{1}+\theta_{2}\right) / 2
$$

where, $\theta_{1}$ is angle of the fan-shaped water film; $\theta_{2}$ is angle of water recess.

The inner radius of the effective load-carrying area is defined as

$$
R_{e 1}=R_{2} \sqrt{\frac{1-\left(R_{1} / R_{2}\right)^{2}}{2 \ln \left(R_{2} / R_{1}\right)}}
$$

where, $R_{1}$ is inner radius of thrust pad; $R_{2}$ is inner radius of water recess.

The outer radius of the effective load carrying area $R_{e 2}$ is defined as

$$
R_{e 2}=R_{4} \sqrt{\frac{1-\left(R_{3} / R_{4}\right)^{2}}{2 \ln \left(R_{4} / R_{3}\right)}}
$$

where, $R_{3}$ is the outer radius of water recess; $R_{4}$ is the outer radius of thrust pad.

Width of the effective load-carrying area in radial direction is

$$
b=R_{e 2}-R_{e 1}
$$

Equivalent radius is defined as

$$
R_{e}=\left(R_{e 1}+R_{e 2}\right) / 2
$$

Arc length of downstream seal dam (No.1) or the upstream seal dam (No.2) is

$$
L=R_{e}\left(\theta_{1}-\theta_{2}\right) / 2
$$

Based on the parallel-plate clearance flow model, the flow rates of the downstream seal dam (No.1) and the upstream seal dam (No.2) are deduced as follows

$$
\begin{aligned}
& Q_{1}=\frac{b h^{3} \Delta p}{12 \mu L}-\frac{1}{2} b h \omega R_{e} \\
& Q_{2}=\frac{b h^{3} \Delta p}{12 \mu L}+\frac{1}{2} b h \omega R_{e}
\end{aligned}
$$

where, $\Delta p$ is the feeding pressure of water pump. 
Considering the centrifugal effect, the flow rates of the outer seal dam (No.3) and the inner seal dam (No.4) are derived as follows

$$
\begin{aligned}
& Q_{3}=\frac{\theta_{e} h^{3}\left[\Delta p+0.15 \rho \omega^{2}\left(R_{4}^{2}-R_{3}^{2}\right)\right]}{12 \mu \ln \left(R_{4} / R_{3}\right)} \\
& Q_{4}=\frac{\theta_{e} h^{3}\left[\Delta p-0.15 \rho \omega^{2}\left(R_{2}^{2}-R_{1}^{2}\right)\right]}{12 \mu \ln \left(R_{2} / R_{1}\right)}
\end{aligned}
$$

Then, the hydraulic power delivered by water pump at each seal dam is given as

$$
N_{p i}=\Delta p Q_{i}, i=1,2,3,4 .
$$

The total hydraulic power delivered by water pump is

$$
N_{p}=\sum_{i=1}^{4} \Delta p Q_{i}, i=1,2,3,4 .
$$

3) Temperature rise of lubricating water of hydrostatic thrust bearing

After introducing an adiabatic assumption between water and bearing, the temperature rise of lubricating water at each seal dam can be obtained based on the first law of thermodynamics, which is as

$$
T_{i}=\frac{N_{f i}+N_{p i}}{c_{p} \rho Q_{i}}, i=1,2,3,4 .
$$

\subsubsection{Heat generation by the rolling bearings}

The friction heat generated in rolling bearings is mainly related to bearing type, physical dimension, rotation speed, magnitude of load, and lubrication condition, which can be calculated by [29]

$$
H_{f}=1.047 \times 10^{-4} n M
$$

where, $n$ is the rotation speed; $M$ is the friction torque.

Until now, there has not been an accurate theoretical model on friction torque of rolling bearings. An empirical formula proposed by Palmgren [29] has been widely adopted to calculate friction torque of rolling bearings, which consists of two parts, one is load independent friction torque $M_{0}$ and another is load dependent friction torque $M_{1} . M$ is expressed as

$$
M=M_{0}+M_{1}
$$

where,

$$
M_{0}=\left\{\begin{array}{l}
10^{-7} f_{0}\left(v_{0} n\right)^{2 / 3} d_{m}^{3}, v_{0} n>2000 \\
160 \times 10^{-7} f_{0} d_{m}^{3}, \quad, v_{0} n \leq 2000
\end{array}\right.
$$

where, $f_{0}$ is a factor related to bearing type and lubrication method, the value of which is 1 for deep groove ball bearing and 2 for self-aligning ball bearing; $v_{0}$ is kinematic viscosity of the lubricant which is as a constant in this study due to the small temperature rise; $\mathrm{dm}$ is the pitch diameter of the bearing.

$$
M_{1}=f_{1} P_{1} d_{m}
$$


where, $f_{1}$ is a factor related to bearing type and load. $P_{1}$ is the bearing preload. $f_{1}$ and $P_{1}$ are expressed as follows

For the self-aligning ball bearing

$$
\begin{gathered}
f_{1}=0.0003\left(\frac{F_{0}}{C_{0}}\right)^{0.4} \\
P_{1}=1.4 Y_{2} F_{a}-0.1 F_{r}
\end{gathered}
$$

For the deep groove ball bearing

$$
\begin{gathered}
f_{1}=0.0009\left(\frac{F_{0}}{C_{0}}\right)^{0.33} \\
P_{1}=3 F_{a}-0.1 F_{r}
\end{gathered}
$$

where, $Y_{2}$ is the axial load factor; $F_{a}$ is the axial load; $F_{r}$ is the radial load; $F_{0}$ is the static equivalent load; $C_{0}$ is the basic static load rating.

\subsection{Thermal Boundary Condition of Spindle System}

The heat transfer process in the spindle system mainly includes: forced convection heat transfer between oil-air lubrication and rolling bearings, forced convection heat transfer between shaft and ambient air, and natural convection heat transfer between stationary components and ambient air.

\subsubsection{Convection between oil-air lubricant and spindle}

The rolling bearings are lubricated as well as cooled efficiently by oil-air mixture. As shown in Fig.1, the oil-air mixture flows into the spindle through an inlet at the spindle housing; and then the mixture flows through the gap between the shaft and the housing and reaches the rolling bearings; finally, the lubricant flows out through the outlet at the housing. The forced convective heat transfer occurs at the shaft surface, the inner surface of spindle housing and the rolling bearings.

The called oil-air mixture, little amount of oil is utilized actually, volume ratio of oil and air is about 1:1010 in this case; accordingly, it is assumed that heat is exchanged only between the spindle and the compressed air. The cross-section area of compressed air flow perpendicular to the shaft is

$$
A_{a x}=\pi \bar{d} \Delta h
$$

where, $\Delta h$ is the radial clearance; $\bar{d}$ is the average diameter of the clearance.

The axial velocity of compressed air is

$$
u_{x}=\frac{Q_{a i r}}{A_{a x}}
$$

where, $Q_{\text {air }}$ is the volumetric flow rate of the compressed air.

The circumferential velocity of compressed air $u_{y}$ is

$$
u_{y}=\frac{\omega \bar{d}}{2}
$$


The mean velocity of compressed air flow is obtained by superimposing axial and circumferential velocities:

$$
\bar{u}=\sqrt{u_{x}^{2}+u_{y}^{2}}
$$

Then, the heat convection coefficient between oil-air lubricant and spindle is calculated using the following empirical equation [5]:

$$
\alpha=9.7+5.33 \times \bar{u}^{0.8}
$$

\subsubsection{Forced Convection Between Shaft and Ambient Air}

For the running shaft surface, according to heat transfer theory [30], the Nusselt number is determined by the following equation

$$
\mathrm{Nu}=0.133 \operatorname{Re}^{2 / 3} \operatorname{Pr}^{1 / 3}
$$

where, Pr is Prandtl number, Re is Reynolds number, which is determined by the following equations

$$
\begin{aligned}
& u=\frac{\pi n d}{60} \\
& \operatorname{Re}=\frac{u d}{v_{0}}
\end{aligned}
$$

where, $u$ is circumferential velocity of shaft surface, $d$ is shaft diameter, $v_{0}$ is kinematic viscosity of air.

Then, the heat transfer coefficient is calculated by

$$
\alpha=\frac{N u \lambda}{d}
$$

where, $\lambda$ is thermal conductivity of air.

As for the end face of shaft, according to heat transfer theory [30], the local Nusselt number at radius $r$ is determined by the following equation

$$
\mathrm{Nu}_{r}= \begin{cases}\frac{0.585 \mathrm{Re}_{r}^{0.5}}{0.6 / \operatorname{Pr}+0.95 / \operatorname{Pr}^{1 / 3}} & , \operatorname{Re} \leq 2.4 \times 10^{5}, \text { any } \operatorname{Pr} \\ 0.21 \mathrm{Re}_{r}^{0.8} \operatorname{Pr}^{1 / 3} & , \operatorname{Re} \geq 2.4 \times 10^{5}, \operatorname{Pr}>0.5\end{cases}
$$

where, $\operatorname{Re}_{r}$ is rotational Reynolds number and is given as

$$
\operatorname{Re}_{r}=\frac{\omega r^{2}}{v_{0}}
$$

Then, the convective heat transfer coefficient between shaft and ambient air is calculated by

$$
\alpha=\frac{\overline{\mathrm{Nu}} \lambda}{r}
$$

\subsubsection{Natural heat transfer}

Natural heat transfer occurs between ambient air and stationary components such as the spindle housing, and the value of $9.7 \mathrm{~W} /\left(\mathrm{m}^{2} \cdot \mathrm{K}\right)$ is adopted for free convection heat transfer coefficient according to related experiment [5]. 


\subsection{Finite element model}

The thermal model for the face machining spindle system was developed with aid of the finite element software (ANSYS), as shown in Fig.4. The thermal element SOLID70 was adopted to simulate the temperature field distribution; and the structural element SOLID92 was applied to calculate the thermal displacement due to temperature rise of the spindle system. To improve the simulation accuracy, elements in thrust bearing and rolling bearings were meshed much more finely than other regions. A grid independence study was performed for the spindle system; the results show that the variation in the solution can be neglected when the spindle system is divided into a total of 269997 solid elements.

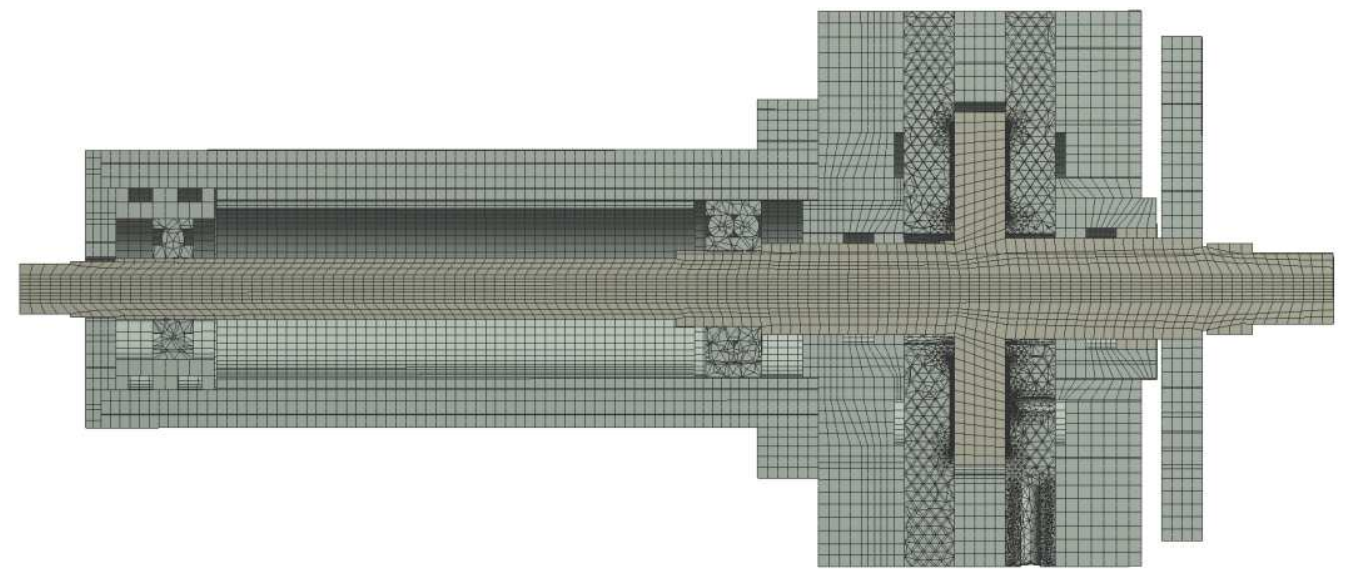

Fig. 4 The thermal model for the spindle using FEM

\section{Result and discussion}

\subsection{Theoretical simulation}

A numerical simulation was performed for the proposed spindle. Set the ambient temperature is $298.15 \mathrm{~K}\left(25^{\circ} \mathrm{C}\right)$, the water supply pressure is $1.0 \mathrm{MPa}$ and rotational speed is $12000 \mathrm{rpm}$. The structural parameters of the water-lubricated hydrostatic thrust bearing are listed in Table 1 . The physical parameters of water at $298.15 \mathrm{~K}\left(25^{\circ} \mathrm{C}\right)$ are listed in Table 2 . By using Eqs. (1)-(22), the temperature rises for each seal dam are obtained, as listed in Table 3, and the first boundary condition is applied to the FEM model. The structural parameters of rolling bearings are listed in Table 4. By using Eqs. (23)-(30), the heat generation of rolling bearings are calculated, as listed in Table 5. The physical parameters of air at $298.15 \mathrm{~K}\left(25^{\circ} \mathrm{C}\right)$ are listed in Table 6 . The volumetric flow rate of compressed air is $0.015 \mathrm{~m}^{3} / \mathrm{s}$ in this study. The thermal boundary condition of the spindle system is obtained using Eqs. (31)-(42), as listed in Table 7. Material parameters of spindle components are listed in Table 8.

Tab. 1 Structural parameters of water-lubricated hydrostatic thrust bearing

\begin{tabular}{cc}
\hline Item & Value \\
\hline Inner radius of pad $R_{1}(\mathrm{~mm})$ & 11 \\
Inner radius of water recess $R_{2}(\mathrm{~mm})$ & 14 \\
Outer radius of water recess $R_{3}(\mathrm{~mm})$ & 32 \\
Outer radius of pad $R_{4}(\mathrm{~mm})$ & 35 \\
Angle of water film $\theta_{1}(\mathrm{deg})$ & 78 \\
Angle of water recess $\theta_{2}(\mathrm{deg})$ & 62 \\
Thickness of water film $h(\mu \mathrm{m})$ & 20 \\
Number of water recesses & 4 \\
\hline
\end{tabular}




\begin{tabular}{|c|c|c|}
\hline Orifice diameter(mm) & & 0.5 \\
\hline \multicolumn{3}{|c|}{ Tab. 2 Physical parameters of water at $298.15 \mathrm{~K}\left(25^{\circ} \mathrm{C}\right)$} \\
\hline \multicolumn{2}{|l|}{ Item } & Value \\
\hline \multicolumn{2}{|l|}{ Density $\rho\left(\mathrm{kg} / \mathrm{m}^{3}\right)$} & 1000 \\
\hline Specific heat capacity $c_{p}(\mathrm{~J} / \mathrm{kg} \cdot \mathrm{K})$ & & 4200 \\
\hline Dynamic viscosity $\mu(\mathrm{Pa} \cdot \mathrm{s})$ & & 0.001 \\
\hline \multicolumn{3}{|c|}{ Tab. 3 Results of temperature rise of lubricating water for each seal dam } \\
\hline No. of seal dam & \multicolumn{2}{|c|}{ Temperature rise $(\mathrm{K})$} \\
\hline$\# 1$ & \multicolumn{2}{|r|}{0.38} \\
\hline$\# 2$ & \multicolumn{2}{|r|}{0.33} \\
\hline$\# 3$ & \multicolumn{2}{|r|}{1.08} \\
\hline \#4 & \multicolumn{2}{|r|}{0.38} \\
\hline \multicolumn{3}{|c|}{ Tab. 4 Parameters of rolling bearings } \\
\hline Item & Deep groove ball bearing & Self-aligning ball bearing \\
\hline Designation & 6001 & 1202 \\
\hline Inner diameter (mm) & 12 & 15 \\
\hline Outer diameter $(\mathrm{mm})$ & 28 & 35 \\
\hline $\begin{array}{l}\text { Distance between inner ring and } \\
\text { outer ring } \Delta h(\mathrm{~mm})\end{array}$ & 3.2 & 4.5 \\
\hline \multicolumn{3}{|c|}{ Tab. 5 Heat generation of rolling bearings } \\
\hline Item & & Value $(W)$ \\
\hline Deep groove ball bearing & & 3.361 \\
\hline Self-aligning ball bearing & & 13.1045 \\
\hline \multicolumn{3}{|c|}{ Tab. 6 Physical parameters of air at $298.15 \mathrm{~K}\left(25^{\circ} \mathrm{C}\right)$} \\
\hline Item & & Value \\
\hline Kinematic viscosity $v_{0}(\mathrm{cSt})$ & & 15.53 \\
\hline Thermal conductivity $\lambda(\mathrm{W} /(\mathrm{m} \cdot \mathrm{K}))$ & & $2.63 \times 10^{-2}$ \\
\hline Prandtl Number Pr & & 0.702 \\
\hline \multicolumn{3}{|c|}{ Tab. 7 Convection heat transfer coefficients } \\
\hline Item & & Value $\left(\mathrm{W} / \mathrm{m}^{2} \cdot \mathrm{K}\right)$ \\
\hline Oil-air lubrication for deep gro & ball bearing & 110.34 \\
\hline Oil-air lubrication for self-align & ball bearing & 82.92 \\
\hline Oil-air lubrication for sha & ousing & 68.59 \\
\hline Shaft surface (diameter & $\mathrm{nm})$ & 81.48 \\
\hline Shaft surface (diameter & $\mathrm{nm})$ & 88.30 \\
\hline Shaft surface (diameter & $\mathrm{nm})$ & 96.02 \\
\hline Shaft surface (diameter & $\mathrm{mm})$ & 170.06 \\
\hline
\end{tabular}




\begin{tabular}{ccc}
\hline $\begin{array}{c}\text { End faces of shaft } \\
\text { Stationary component }\end{array}$ & 71.95 \\
\multicolumn{2}{c}{ Tab. 8 Material parameters } & 9.7 \\
\hline Item & Shaft & Other main components \\
\hline Material & $40 \mathrm{Cr}$ & 45 steel \\
Density $\left(\mathrm{kg} / \mathrm{m}^{3}\right)$ & 7900 & 7850 \\
Young's modulus $(\mathrm{Pa})$ & $2.1 \times 10^{11}$ & $2 \times 10^{11}$ \\
Poisson's ratio & 0.3 & 0.3 \\
Thermal conductivity $(\mathrm{W} /(\mathrm{m} \cdot \mathrm{K}))$ & 32.6 & 60.5 \\
Coefficient of thermal expansion $\left(\mathrm{K}^{-1}\right)$ & $1.17 \times 10^{-5}$ & $1.2 \times 10^{-5}$ \\
Specific heat capacity $(\mathrm{J} /(\mathrm{kg} \cdot \mathrm{K}))$ & 460 & 465 \\
\hline
\end{tabular}

Figure 5 illustrates the steady-state temperature distribution of the spindle system. It can be seen that the maximum temperature rise of the spindle system is $1.291 \mathrm{~K}$, which locates at the outer seal dam of the thrust pad. The maximum temperature rise of the self-aligning ball bearing is about $0.709 \mathrm{~K}$. The steady-state thermal deformation of the spindle system is shown in Fig.6.

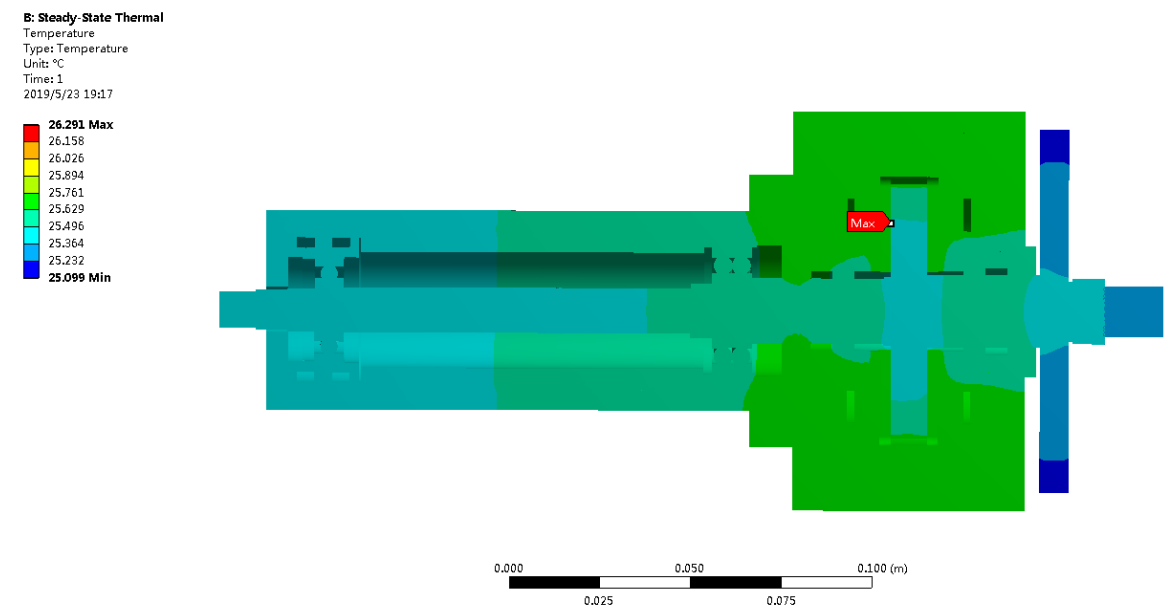

Fig. 5 Steady-state temperature distribution of the spindle system

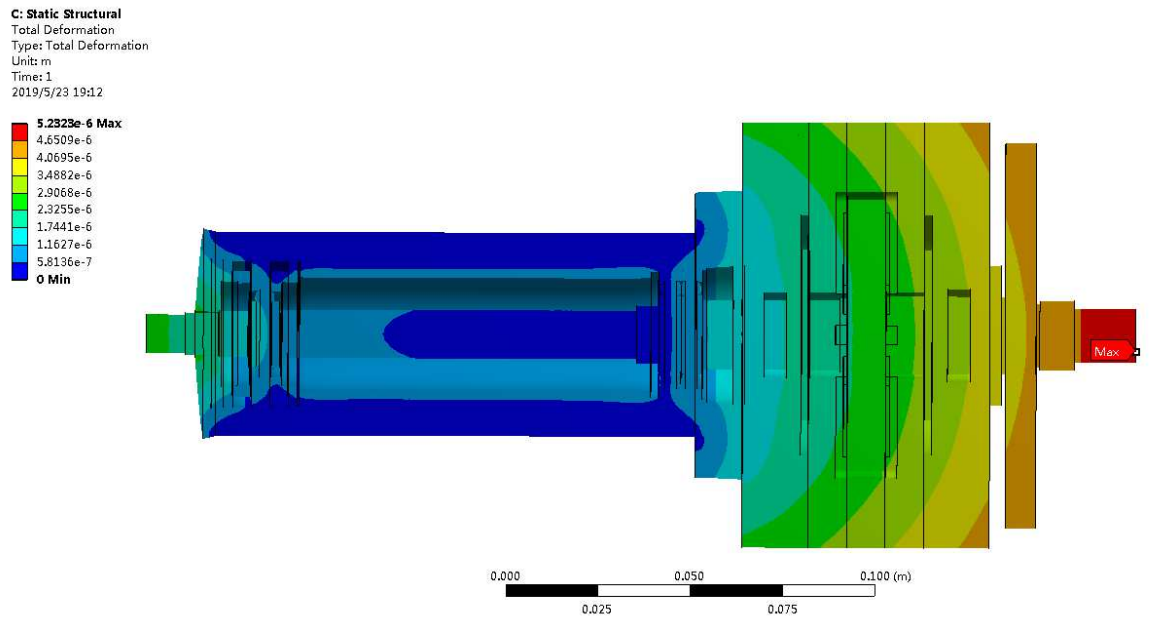

Fig. 6 Steady-state thermal displacement distribution of the spindle system 


\subsection{Experimental validation}

An experimental prototype of the face-grinding spindle supported by the water-lubricated hydrostatic thrust bearing and the rolling bearings was developed. A temperature rise was measured using the experimental prototype to verify the thermal model.

Figure 7 (a) illustrates the schematic diagram of the experiment setup. The left end of the face-grinding spindle is connected to a motorized spindle using a flexible coupling. The motorized spindle is utilized to drive the face-grinding spindle. Total 17 thermocouples (HH-K-24K, accuracy $0.1 \mathrm{~K}$ ) are used to measure the temperature rises of the bearings. Specially, 16 thermocouples locate at the left and the right thrust bearing pads to measure the temperature rises of outer seal dams and water return chutes, their positions and labels are shown in Fig.7(a); 1 thermocouple locates at the outer ring of the self-aligning ball bearing. The temperature signals are sampled and analyzed using a temperature acquisition and analysis equipment (NI PXIe).

The test result shows that, as to the left side of the thrust bearing, the temperature rises detected by thermocouples of Nos.1, 3, 5 and 7 are almost equal, and the temperature rises of Nos.2, 4, 6 and 8 are also almost equal. The temperature differences among all 8 thermocouples are less than $0.2 \mathrm{~K}$. As to the right side, the temperature rises are basically identical with those of the left side. To save space, test values of Nos.1 and 9 are selected to show the temperature rises of outer seal dams, and the test ones of Nos.2 and 10 are for those of the water return chutes.

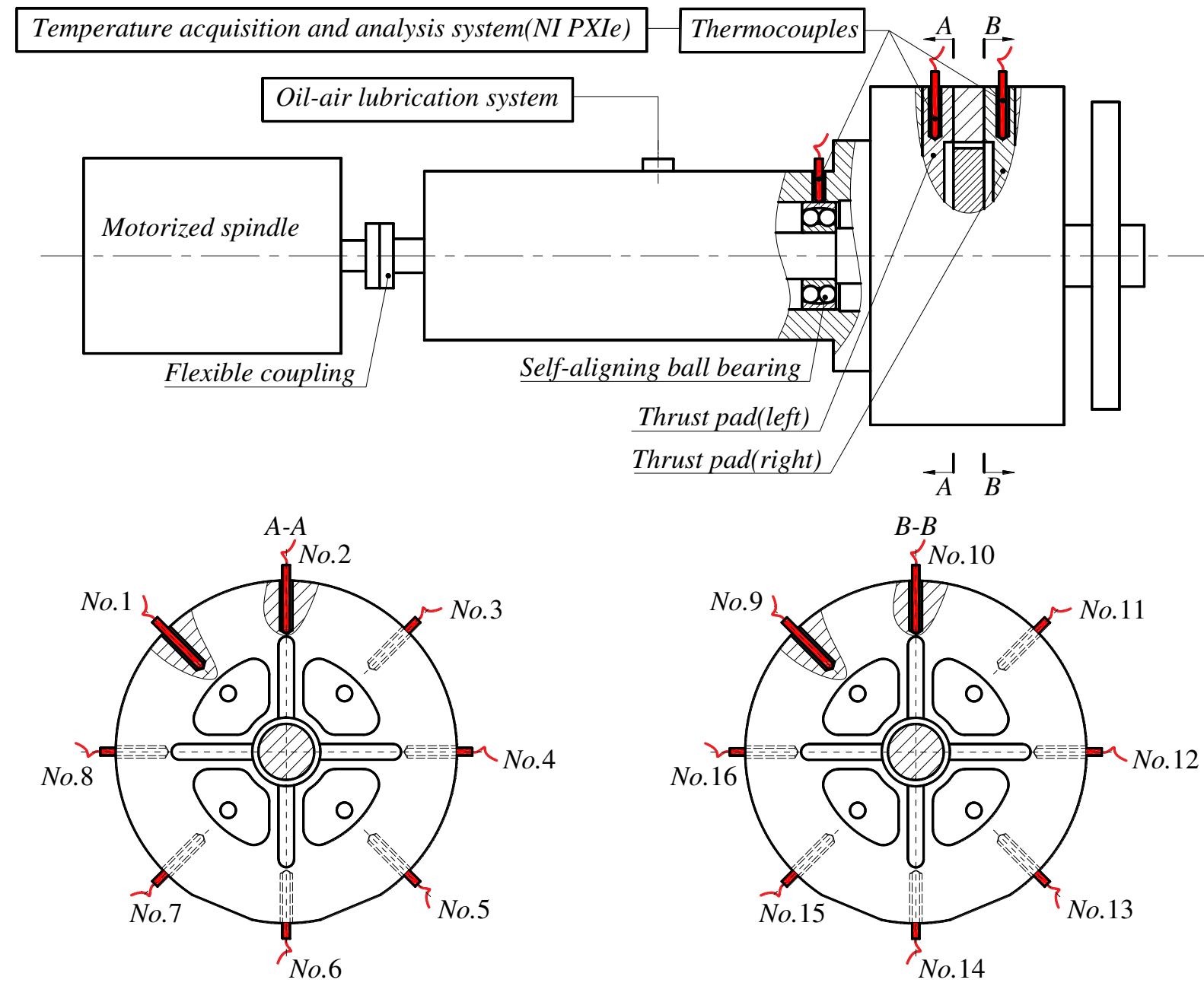

(a) Schematic view of test system 


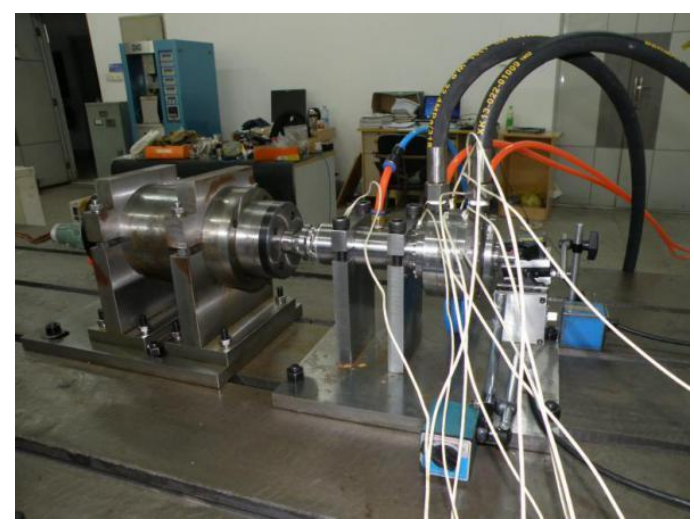

(b) Real scene image

Fig. 7 The experiment setup of the proposed spindle for the temperature rise

Figure 8 shows the transient temperature rises of the water-lubricated hydrostatic thrust bearing under different rotational speeds. It can be seen that the temperature rises of two pads increase after startup of the spindle, and the pads attain heat equilibrium state within a 100-150 second running; in addition, the temperature rises of two pads together with the thermal equilibrium time increase with the increasing of rotational speed. As expected, the temperature rises of the left pad and the right pad are basically equal. An explanation for this result may be that the water film shearing increases with the increasing of rotational speed, leading to a high temperature rise of the water-lubricated thrust bearing; and the higher the temperature rise, the longer time the thermal equilibrium time of the spindle. In this case, one significant result for the water-lubricated hydrostatic thrust bearing is that its steady temperature rise is less than $2.5 \mathrm{~K}$.
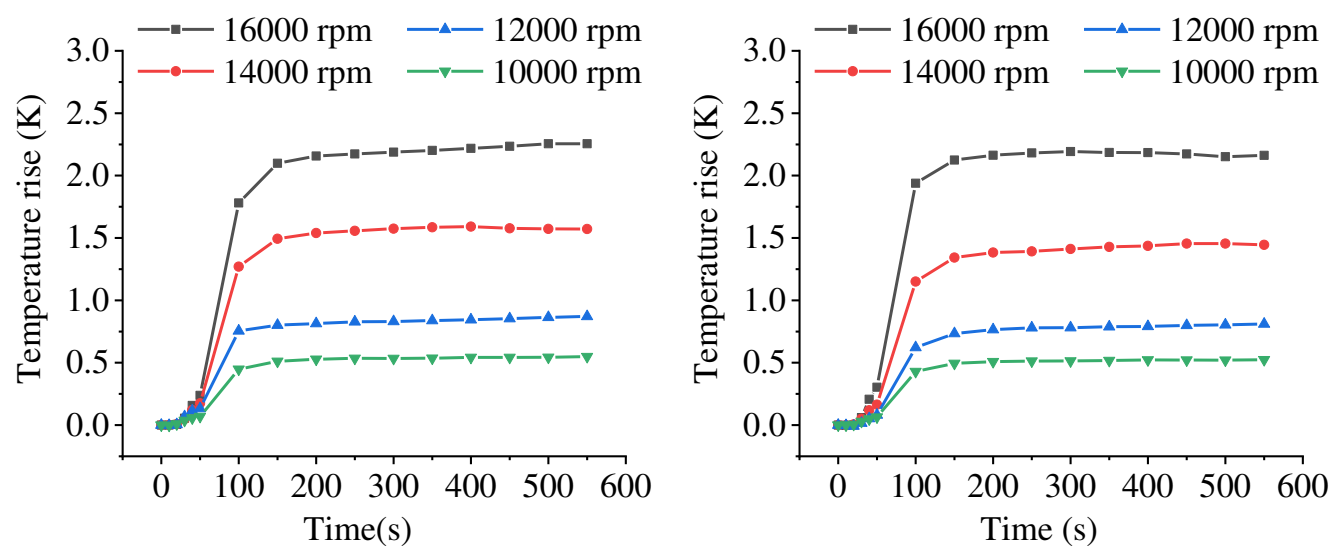

(a) Outer seal dam of the left pad (No.1)

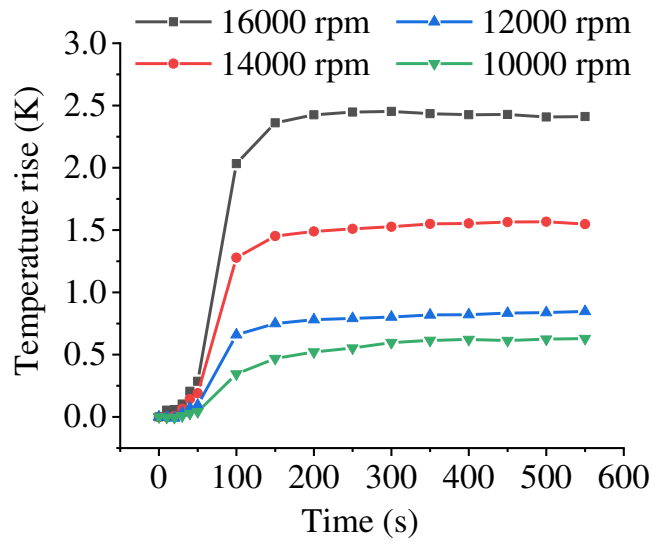

(b) Water return chute of the left pad (No.2)

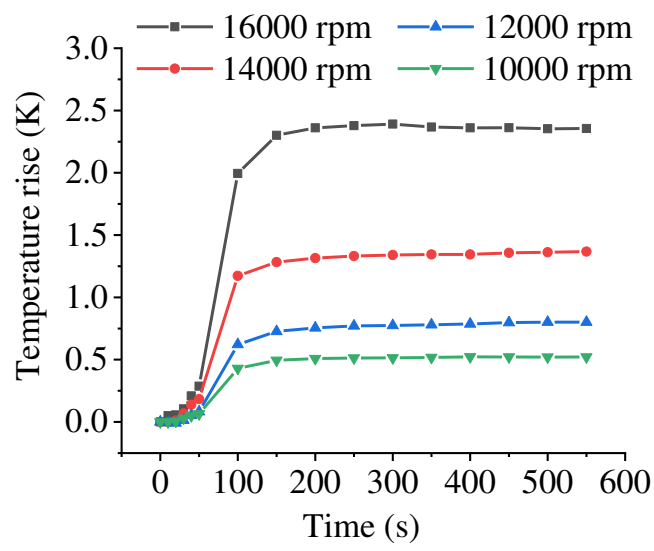

(c) Outer seal dam of the right pad (No.9)

(d) Water return chute of the right pad (No.10)

Fig. 8 Experimental transient temperature rises of the water-lubricated hydrostatic thrust bearing 
Figure 9 shows the transient temperature rises of the self-aligning ball bearing under four rotational speeds. It can be seen that the temperature rise of the self-aligning ball bearing increases obviously with the increasing of rotational speed. Compared with the water-lubricated hydrostatic thrust bearing, the self-aligning ball bearing with oil-air lubrication takes a fairly longer time to reach thermal equilibrium, and the thermal equilibrium time of the rolling bearings increases with the rotational speed. This result may be explained by the fact that the bearing frictional power loss increases with the increasing of rotational speed, leading to a high temperature rise of the rolling bearing; and the higher the temperature rise, the longer time the thermal equilibrium time of the spindle. The experimental result shows that the steady temperature rise of the rolling bearing is much less than that of the water-lubricated thrust bearing. For consistency, the result about the self-aligning ball bearing is shown within test time of 550s.

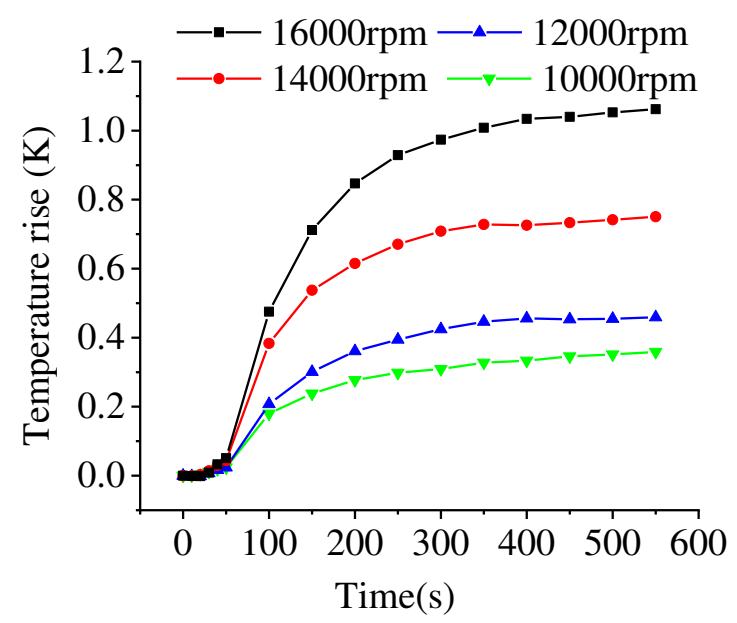

Fig. 9 Experimental transient temperature rises of the self-aligning ball bearing

Figure 10 displays a comparison of the steady temperature rises of hydrostatic thrust bearing and self-aligning ball bearing between the simulated result and the experimental one. It can be seen that the simulated values are generally agreeable with the experimental ones. The same trend for the two types of bearing is that the simulated values are higher than the experimental ones when the spindle operates at a lower speed; while the simulated values are lower than the experimental ones when the spindle at a higher speed. To give a possible explanation for this result, the Reynolds number of the hydrostatic thrust bearing was calculated, and the calculated result shows that the Reynolds number is 1700 as the bearing runs at $12000 \mathrm{rpm}$, while it is 2300 as the bearing runs at 16000rpm. According to the judging criterion of flow state, when the range of bearing speed is from 12000rpm to 16000rpm, the water lubricant is in a laminar state but close to turbulent one. However, the laminar model is utilized to calculate the temperature rise of the water-lubricated hydrostatic thrust bearing, so it seems possible that the simulated values are lower than the experimental ones when the spindle runs at a higher speed. It is found by a further observation that the theoretical and experimental error of the thrust bearing is significantly smaller than that of the self-aligning ball bearing. Those errors may be attributed to many aspects: (1) Several assumptions are introduced when modeling, especially for rolling bearings with oil-air lubrication; (2) There exists a machining error and an assembly error for the water-lubricated thrust bearing; (3) The temperature rise of the spindle system is relatively small, as a result, the measuring error of temperature sensors accounts for an essential portion of experimental value. 


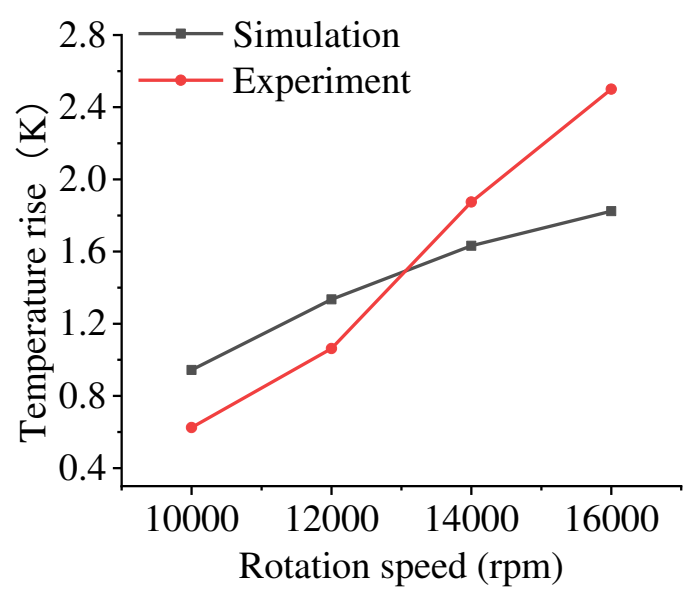

(a) Thrust bearing

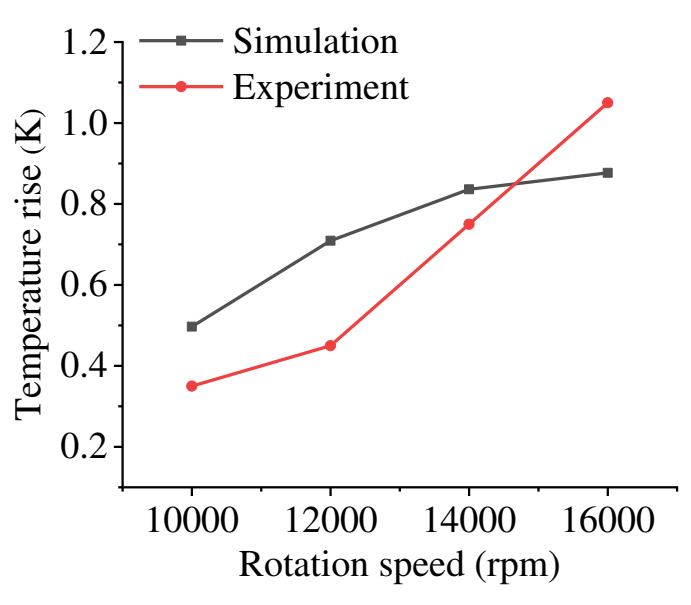

(b) Self-aligning ball bearing

Fig. 10 The simulated temperature rises vs. the experimental ones

\subsection{Effect of eccentricity ratio on temperature rise of the water-lubricated hydrostatic thrust bearing}

When an external axial load is applied to the spindle end, a displacement will appear for the thrust plate. Under this condition, the static characteristics of the water-lubricated hydrostatic thrust bearing including the frictional power loss, the flow rate and the temperature rise was calculated using Eqs. (16)-(22) in this study.

Figure 11 denotes the variation of static characteristics of the water-lubricated hydrostatic thrust bearing with the eccentricity ratio. The calculated result indicates that the frictional power loss of the bearing's left side decreases while that of the right side increases with the increasing of eccentricity ratio, the total frictional power loss of the bearing increases with the eccentricity ratio. Simultaneously, the flow rate of the bearing's left side also decreases while that of the right side increases slightly due to the damping effect of orifice, the total frictional power loss of the bearing decreases with the eccentricity ratio. On the contrary, the temperature rise of the bearing's left side increases apparently while that of the right side decreases slightly with the increasing of eccentricity ratio. Totally, the temperature rise of the thrust bearing between the outlet and the inlet increases slightly when the eccentricity ratio is less than 0.3. As to the water-lubricated hydrostatic thrust bearing in engineering application, the designed eccentricity ratio is less than 0.3 . As a result, the effect of eccentricity ratio on the temperature rise of the water-lubricated hydrostatic thrust bearing is not prominent when the eccentricity ratio is within a small value.

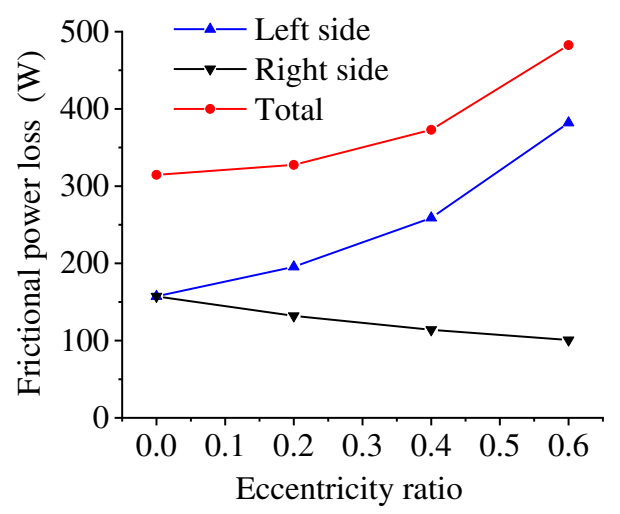

(a) Frictional power loss 


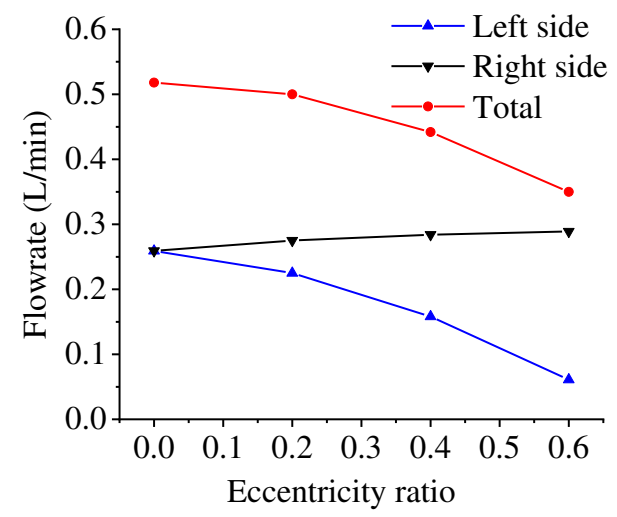

(b) Flow rate

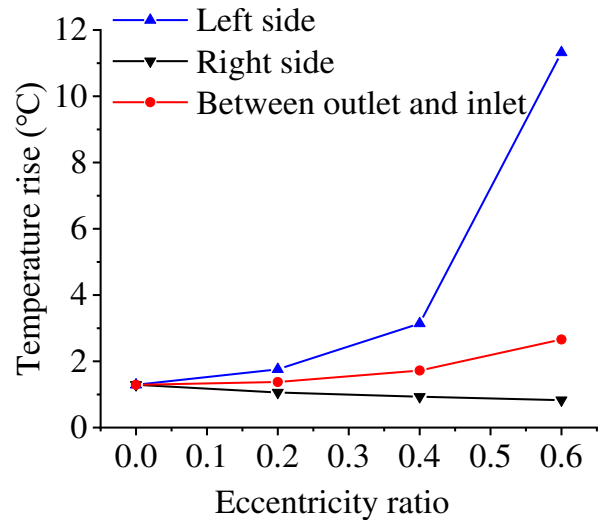

(c) Temperature rise

Fig.11 Effect of eccentricity ratio on the temperature rise of the water-lubricated hydrostatic thrust bearing

$$
(n=12000 \mathrm{rpm})
$$

\subsection{Comparison of comprehensive characteristics between the spindle supported by rolling bearings and the} replacement spindle designed with proposed combined support

To demonstrate the advantage of the proposed system, a comparative study of comprehensive characteristics between an ordinary face-grinding spindle with the rolling ball bearings and the replacement spindle with proposed combined support is conducted. In this case, the rim velocity of grinding wheel is set as $35 \mathrm{~m} / \mathrm{s}$, and the outer diameter of the face-grinding wheel is $750 \mathrm{~mm}$, so the rotational speed of spindle is $900 \mathrm{rpm}$. As to the spindle supported by the rolling ball bearings, according to the design criteria, two pairs of duplex bearings with a $120 \mathrm{~mm}$ inner diameter should be utilized to support the spindle, as shown in Fig.12(a). The replacement spindle using the proposed combined support is shown in Fig.12(b), based on the calculation result, the parameters of water-lubricated hydrostatic thrust bearing are determined and list in Table 9. The inner diameters of the self-aligning ball bearing and the deep groove ball bearing for the later spindle are also denoted in Fig.12(b). 


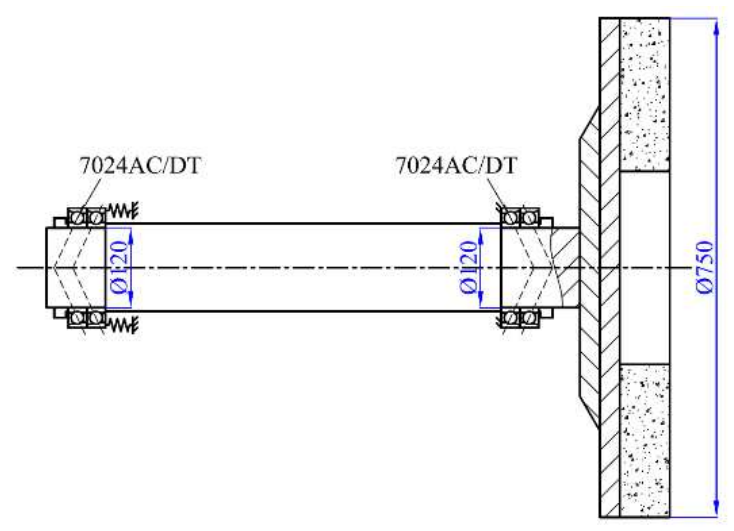

(a) Rolling bearings

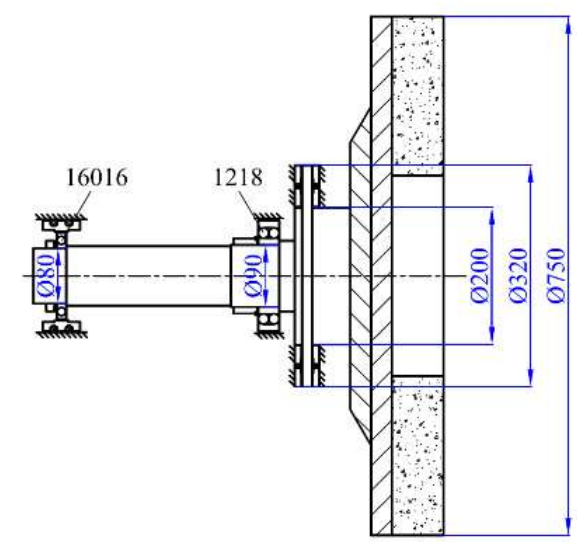

(b) Proposed combined support

Fig.12 The spindle supported by rolling bearings and the replacement spindle designed with proposed combined support Tab. 9 Parameters of water-lubricated thrust bearing

\begin{tabular}{cccc}
\hline Item & Value & Item & Value \\
\hline$R_{1}$ & $100 \mathrm{~mm}$ & $R_{2}$ & $120 \mathrm{~mm}$ \\
$R_{3}$ & $140 \mathrm{~mm}$ & $R_{4}$ & $160 \mathrm{~mm}$ \\
$\theta_{1}$ & $80 \mathrm{deg}$ & $\theta_{2}$ & $60 \mathrm{deg}$ \\
$h_{0}$ & $30 \mu \mathrm{m}$ & $\varepsilon$ & 0 \\
$P s$ & $1.5 \mathrm{MPa}$ & & \\
\hline
\end{tabular}

\subsubsection{The face-grinding spindle with the rolling ball bearings}

The axial stiffness of the face-grinding spindle with the rolling ball bearings is equal to the axial stiffness of the front duplex bearings, which is calculated using the method proposed by the authors in Ref. [31]. Fig.13 shows the axial stiffness decreases slightly with the rotational speed, and the axial stiffness of the face-grinding spindle is about $265 \mathrm{~N} / \mu \mathrm{m}$ at $900 \mathrm{rpm}$. The temperature rise of the rolling bearing under oil-air lubrication can refer to our test result published in Ref. [32], which can exceed $10^{\circ} \mathrm{C}$ based on the equivalence of bearing's DN value. It should be mentioned that the temperature rise of the rolling bearing under grease lubrication is much higher than that under oil-air lubrication. The axial runout of the precision rolling bearing with an inner diameter of $120 \mathrm{~mm}$ can reach $2-3 \mu \mathrm{m}$ by practical engineering result. 


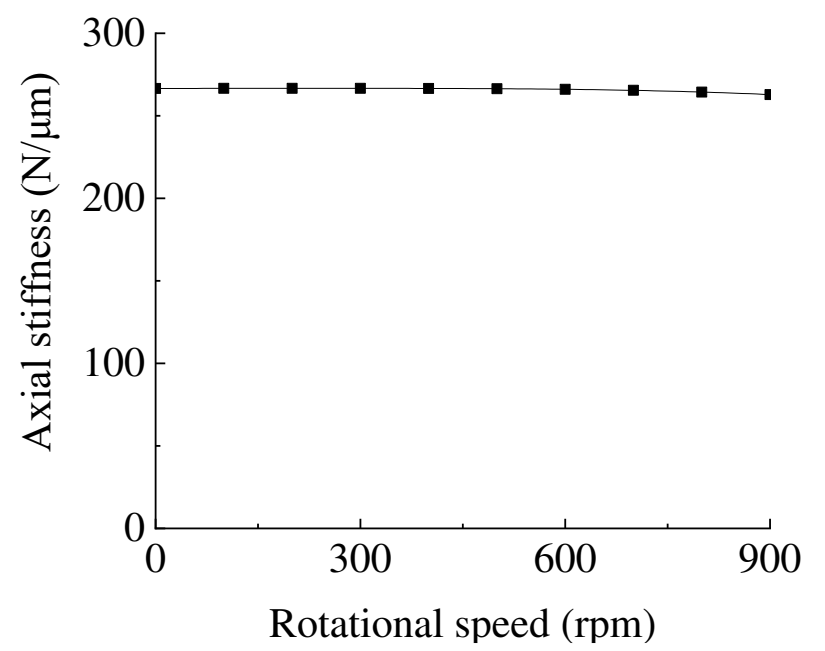

Fig.13 The variation of simulated axial stiffness with the rotational speed

\subsubsection{The face-grinding spindle with the proposed support}

The axial stiffness of the face-grinding spindle with the proposed support is entirely dependent on the axial stiffness of the water-lubricated hydrostatic thrust bearing, which can be calculated using the method proposed by the authors in Ref. [33]. Fig.14 shows the variation of axial stiffness with the orifice diameter. In this case, the orifice with diameter of $1.3 \mathrm{~mm}$ is adopted for the thrust bearing, so the axial stiffness of the face-grinding spindle can reach the maximum value of $1935 \mathrm{~N} / \mu \mathrm{m}$. The flow rate and temperature rise of the water-lubricated hydrostatic thrust bearing are solved using Eqs. (16)-(22) in this study, the results are illustrated in Fig.15. In practical engineering, the axial runout of the water-lubricated hydrostatic thrust bearing with a $160 \mathrm{~mm}$ radius can be less than $1 \mu \mathrm{m}$ due to homogenization effect of fluid film.

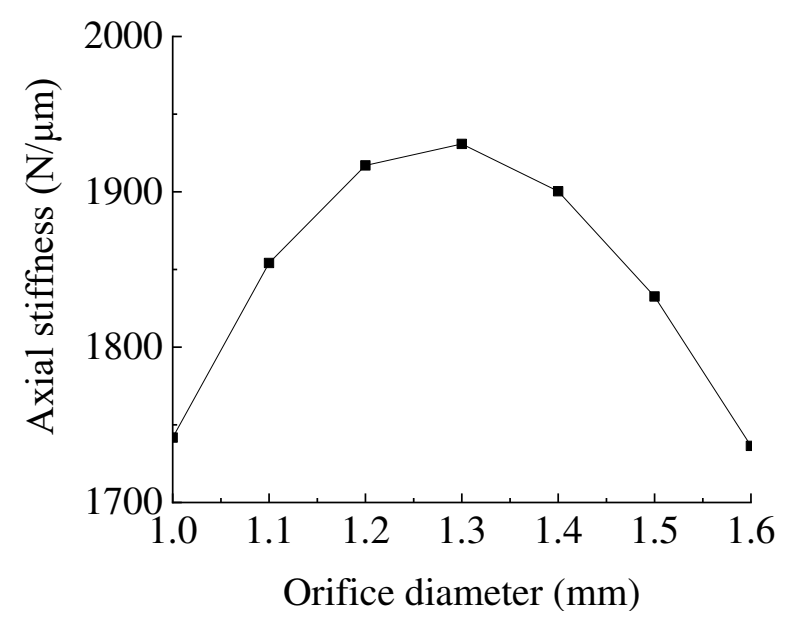

Fig.14 The variation of simulated axial stiffness with the orifice diameter 


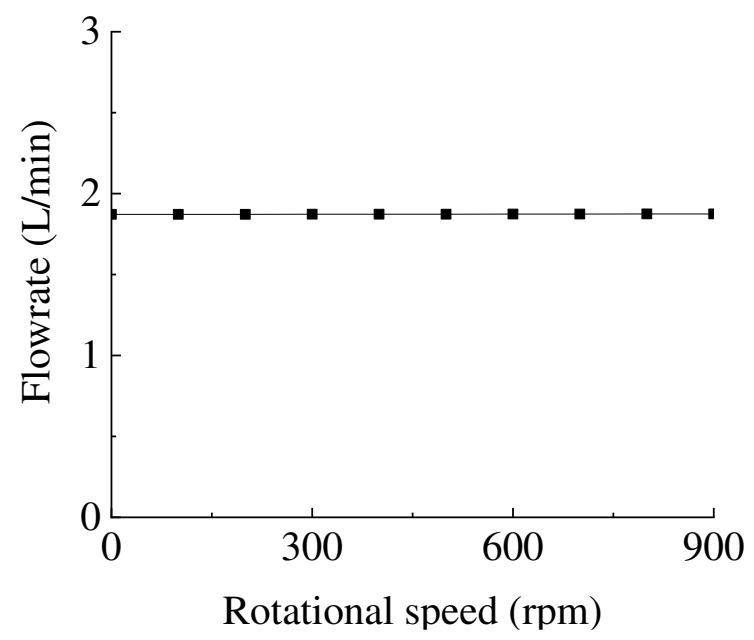

(a) Flow rate of single recess

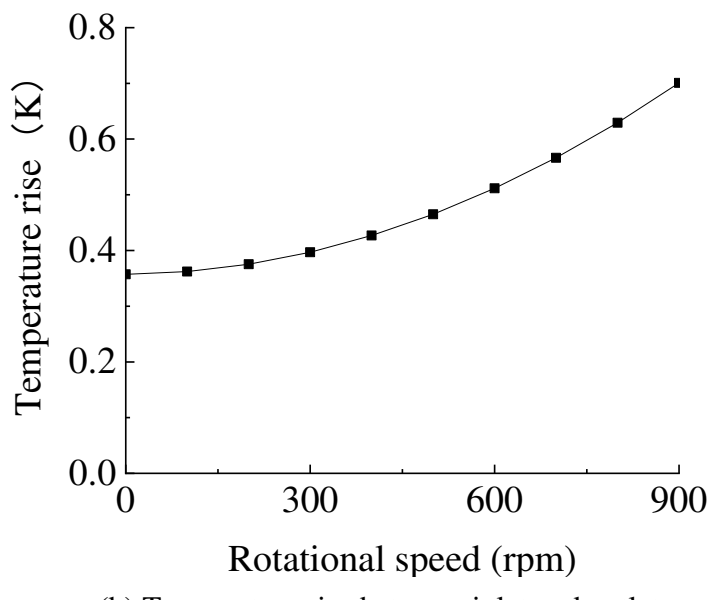

(b) Temperature rise between inlet and outlet

Fig. 15 The simulated flow rate and temperature rise of the water-lubricated hydrostatic thrust bearing

Through a comparison of the main static characteristics between the two types of the spindle, it can be found that the proposed face-grinding spindle has advantage in axial stiffness, bearing temperature rise, and axial runout, etc.

In this section, the outer diameter of the face-grinding wheel is supposed to be $750 \mathrm{~mm}$, the manufacturing for those spindles is too expensive for us, and the test study also needs spacious experimental conditions, which is also beyond the ability of our laboratory. So we can not give the actual experimentally measured results for the comprehensive performances of the spindles.

In machining process, the cutting forces acting on the spindle end include the main cutting force along the tangential direction, the feed force along the radial direction and the cutting force along the axial direction. The amplitude of axial cutting force is much larger than the other two cutting forces [34-36]. Thus, the large-size hydrostatic thrust bearing is capable of carrying the large axial cutting force, meanwhile, the small-diameter rolling bearings are suitable for supporting the other two radial small-amplitude forces. The above study shows that heat generation of water-lubricated hydrostatic thrust bearing is small due to low viscosity of water. Therefore, the water-lubricated hydrostatic thrust bearing can operate at high speed, while its temperature rise is low. Hence, the proposed face-grinding spindle with the large-size thrust bearing and small-diameter rolling bearings is promising to be found an application in the large-size face-grinding condition. 


\section{Conclusions}

This study proposes an improved face-grinding spindle supported by a combined bearings including a water-lubricated hydrostatic thrust bearing and two rolling bearings with oil-air lubrication system. The thermal model for the proposed face-grinding spindle is established. Test study is carried out using the developed experiment prototype to verify the thermal model. A comparative study of comprehensive characteristics between the spindle supported by rolling bearings and the replacement spindle designed with proposed combined support is conducted. Based on the result and discussion, the following conclusion can be drawn:

1) The water-lubricated hydrostatic thrust bearing can be modeled based on the law of Newton's inner friction, the hydrostatic theory and the first law of thermodynamics. The rolling bearing with oil-air lubrication can be modeled based on the rolling bearing moment formula and the convective heat transfer theory. According to the first law of thermodynamics, the thermal model for the proposed spindle can be established with the aid of FEM.

2) Compared with the spindle supported by rolling bearings, the replacement spindle designed with proposed combined support has technical advantage of low temperature rise, large axial stiffness and low rotation accuracy, etc.

3) The technical advantage of the proposed spindle is mainly contributed to the water-lubricated hydrostatic thrust bearing, and the effect of eccentricity ratio on the temperature rise of the thrust bearing is not prominent when the eccentricity ratio is within a small value. The temperature rises of the rolling bearings are low due to the high-efficient cooling ability of oil-air lubrication system and the usage of rolling bearings with small size.

Acknowledgement This work is financially supported by the National Natural Science Foundation of China (Nos. 51635004, 12172088).

Author contribution Shuyun Jiang: Conceptualization, Methodology, Funding acquisition, Writing - Review \& Editing; Shengye Lin: Software, Validation, Writing - Original Draft; Fukang Liu: Writing - Original Draft

Availability of data and materials All data generated or analysed during this study are included in this published article.

\section{Declarations}

Ethics approval Not applicable.

Consent to participate Not applicable.

Consent for publication The authors declare that they have no known competing fnancial interests or personal relationships that could have appeared to infuence the work reported in this paper.

Competing interests The authors declare no competing interests.

\section{References}

1. Abele E, Altintas Y, Brecher C (2010) Machine tool spindle units. CIRP Annals-Manufacturing Technology 59(2):781-802

2. Brecher C, Spachtholz G, Paepenmüller F (2007) Developments for high performance machine tool spindles. CIRP Annals 56(1): 395-399 
3. Liu Y, Ma Y, Meng Q, Xin X, Ming S (2018) Improved thermal resistance network model of motorized spindle system considering temperature variation of cooling system. Advances in Manufacturing 6(4): 384-400

4. Liu Z, Pan M, Zhang A, Zhao Y, Yang Y, Ma C (2015) Thermal characteristic analysis of high-speed motorized spindle system based on thermal contact resistance and thermal-conduction resistance. The International Journal of Advanced Manufacturing Technology 76(9-12): 1913-1926

5. Bossmanns B, Tu J F (1999) A thermal model for high speed motorized spindles. International Journal of Machine Tools and Manufacture 39(9): 1345-1366

6. Bossmanns B, Tu J F (2001) A power flow model for high speed motorized spindles - heat generation characterization. ASME Journal of Manufacturing Science and Engineering 123(3): 494-505

7. Meng Q, Yan X, Sun C, Liu Y (2020) Research on thermal resistance network modeling of motorized spindle based on the influence of various fractal parameters. International Communications in Heat and Mass Transfer 117: 104806

8. Ma C, Yang J, Zhao L, Mei X, Shi H (2015) Simulation and experimental study on the thermally induced deformations of high-speed spindle system. Applied Thermal Engineering 86: 251-268

9. Ma C, Zhao L, Shi H, Mei X, Yang J (2017) Experimental and simulation study on the thermal characteristics of the high-speed spindle system. Proceedings of the Institution of Mechanical Engineers, Part C: Journal of Mechanical Engineering Science 231(6): 1072-1093

10. Creighton E, Honegger A, Tulsian A, Mukhopadhyay D (2010) Analysis of thermal errors in a high-speed micro-milling spindle. International Journal of Machine Tools and Manufacture 50(4): 386-393

11. Haitao Z, Jianguo Y, Jinhua S (2007) Simulation of thermal behavior of a CNC machine tool spindle. International Journal of Machine Tools and Manufacture 47(6): 1003-1010

12. Uhlmann E, Hu J (2012) Thermal modelling of a high speed motor spindle. Procedia CIRP 1: 313-318

13. Cui Y, Li H, Li T, Chen L (2018) An accurate thermal performance modeling and simulation method for motorized spindle of machine tool based on thermal contact resistance analysis. The International Journal of Advanced Manufacturing Technology 96(5-8): 2525-2537

14. Liang F, Gao J, Xu L (2020) Investigation on a machining motorized spindle with miniature-revolving-heat-pipes central cooling structure. International Communications in Heat and Mass Transfer 112: 104502

15. Liu Y, Wang X, Zhu X, Zhai Y (2020) Thermal error analysis of spindle based on temperature-deformation mode. 2020 4th International Conference on Robotics and Automation Sciences (ICRAS), Wuhan, China

16. Zhang L, Li J. Wu Y, Zhang K, Wang Y (2018) Prediction model and experimental validation for the thermal 
deformation of motorized spindle. Heat and Mass Transfer 54(9): 2691-2704

17. Kondo R, Kono D, Matsubara A (2020) Evaluation of machine tool spindle using carbon fiber composite. International Journal of Automation Technology 14(2): 294-303

18. Yang Y, Du Z, Feng X, Yang J (2021) Real-time thermal modelling approach of a machine tool spindle based on bond graph method. The International Journal of Advanced Manufacturing Technology 113(1-2): 99-115

19. Kim S, Lee S (2001) Prediction of thermo-elastic behavior in a spindle-bearing system considering bearing surroundings. International Journal of Machine Tools \& Manufacture 41(6): 809-831

20. Kim B, Bae G, Kim G (2015) A study on the thermal characteristics of the machining machine applied hydrostatic bearing. Transactions of the Canadian Society for Mechanical Engineering 39(3): 717-728

21. Nakao Y, Kirigaya R, Fedorynenko D, Hayashi A, Suzuki K (2019) Thermal characteristics of spindle supported with water-lubricated hydrostatic bearings. International Journal of Automation Technology, 13(5): 602-609

22. Chen D, Bonis M, Zhang F, Dong S (2011) Thermal error of a hydrostatic spindle. Precision Engineering 35(3): $512-520$

23. Su H, Lu L, Liang Y, Zhang Q, Sun Y (2014) Thermal analysis of the hydrostatic spindle system by the finite volume element method. The International Journal of Advanced Manufacturing Technology 71(9-12): 1949-1959

24. Chen D, Fan J, Li H, Wang X, Zhang F (2013) Thermal influence of the couette flow in a hydrostatic spindle on the machining precision. Chinese Journal of Mechanical Engineering 26(3): 427-436

25. Huang Z, Xu K, Wang L, Wang Z, Heng F, Gui L (2016) Thermal characteristics analysis of the spindle system of heavy duty horizontal lathe. Journal of University of Electronic Science and Technology of China 45(06): $1020-1026$

26. Jiang S, Shen D (2018) Research on thermal characteristics of spindle system with tilting pad bearing. ASME Journal of Thermal Science and Engineering Applications 10(5): 051005

27. Jang G H, Kim K S, Lee H S, Kim C S (2004) Analysis of a hydrodynamic bearing of a HDD spindle motor at elevated temperature. ASME Journal of Tribology 126(2): 353-359

28. Mayr J, Jedrzejewski J, Uhlmann E, Alkan Donmez M, Knapp W, Härtig F, Wendt K, Moriwaki T, Shore P, Schmitt R, Brecher C, Würz T, Wegener K (2012) Thermal Issues in Machine Tools. CIRP Annals 61(2): 771-791

29. Palmgren A (1959) Ball and Roller Bearing Engineering. Philadelphia: SKF Industries Inc, Burbank.

30. Mill A F (1995) Basic Heat and Mass Transfer. Irwin, Chicago, II. ISBN:0-256-16388-X

31. Lin S Y, Jiang S Y (2018) Study of the stiffness matrix of preloaded duplex angular contact ball bearings. ASME Journal of Tribology 141(3): 032204 
32. Jiang S Y, Mao H B (2011) Investigation of the high speed rolling bearing temperature rise with oil-air lubrication. ASME Journal of Tribology 133(2): 655-664

33. Lin S Y (2020) Study on the rotor dynamics of face machining spindle with different types of bearings. Ph.D. thesis, Southeast University, Nanjing (in Chinese).

34. Lal G K (1968) Forces in vertical surface machining. International Journal of Machine Design and Research 8 (1): $33-43$

35. Srihari G, Lal G K (1994) Mechanics of vertical surface machining. Journal of Materials Processing Technology 44 (1-2): $14-28$

36. Zhou K, Ding H H, Zhang S Y, Guo J, Liu Q Y, Wang W J (2019) Modelling and simulation of the machining force in rail machining that considers the swing angle of the machining Stone. Tribology International 137: 274-288 